\title{
BMJ Global Health Building operational public health capacity through collaborative networks of National Public Health Institutes
}

\author{
Robert Verrecchia (D) , ${ }^{1,2}$ Osman Dar, ${ }^{1}$ Olaa Mohamed-Ahmed, ${ }^{2}$ Neil Squires ${ }^{2}$
}

To cite: Verrecchia R, Dar 0 , Mohamed-Ahmed 0, et al. Building operational public health capacity through collaborative networks of National Public Health Institutes. BMJ Global Health 2019;4:e001868. doi:10.1136/ bmjgh-2019-001868

Handling editor Seye Abimbola

Received 24 July 2019

Revised 23 September 2019

Accepted 28 September 2019

\section{ABSTRACT}

The strengthening of public health systems internationally is integral to the improvement and protection of global population health. Essential public health functions and services are provided for by a range of organisations working together, often co-ordinated and strategically led by national Ministries of Health. Increasingly, however, National Public Health Institutes (NPHIs) are being developed to better integrate and support the delivery of these services. In this paper, we outline the role of NPHIs analyse their advantages and shortcomings, and explore their potential to deliver enhanced public health through collaborative networking as well as partnership with WHO.

\section{INTRODUCTION}

The strengthening of public health systems internationally is integral to the improvement and protection of global population health. Essential public health functions and services are provided for by a range of organisations working together, often co-ordinated and strategically led by national Ministries of Health. Increasingly, however, National Public Health Institutes (NPHIs) are being developed to better integrate and support the delivery of these services.

\section{THE ROLE OF NPHIS}

Check for updates

(c) Author(s) (or their employer(s)) 2019. Re-use permitted under CC BY-NC. No commercial re-use. See rights and permissions. Published by BMJ.

${ }^{1}$ The Centre on Global Health Security, Chatham House, Royal Institute of International Affairs, London, UK

${ }^{2}$ Global Public Health Division, Public Health England, London, UK

Correspondence to Dr Robert Verrecchia; robert.verrecchia@phe.gov.uk
Though their core functions can be broadly summarised as the monitoring and response to health threats, promotion of programmes to prevent disease and support to health policy-making, ${ }^{1}$ there is significant variation in NPHI activities across the world. Many focus on infectious disease control while others have a more comprehensive public health remit. 'Essential Public Health Functions' have been defined and categorised into frameworks by organisations including regional $\mathrm{WHO}$ offices and the European Commission. Major frameworks for these functions are given in table 1 and in some cases have been adapted for regional need. For example, only the WHO PAHO and WHO EMRO frameworks
Summary box

Public health institutions play an increasingly important role in the delivery of essential public health functions.

- Collaborative international networks are being used to strengthen public health institutions, but their potential may not yet be fully realised.

- Such networks have strong potential for complementing and partnering with WHO in its ambition to achieve strengthened global public health.

- Peer learning between institutions represents a powerful, yet flexible approach to strengthening that can empower all participants.

specifically highlight the response to disasters as essential functions, likely informed by the prevalence of natural hazards in the regions. While these frameworks all vary in detail, their overarching purpose remains the same: to demonstrate what functions are necessary to provide comprehensive public health services at the national and subnational levels. ${ }^{2}$

Many countries such as Brazil and Finland established NPHIs decades ago, while others came into existence more recently. Some of these were formed in response to public health challenges that highlighted a need for specific capacity, leadership and co-ordination, such as the Public Health Agency of Canada, which was formed following the 2002-2003 SARS outbreak. Others resulted from the restructuring of public health services such as in the UK and China. Over the past decade, there has been an increasing recognition of the value that NPHIs bring, particularly in low-income and middle-income countries (LMICs), and thus many of these countries have formed new NPHIs, often with the support of grant money mobilised through the International Association of National Public Health Institutes (IANPHI). ${ }^{3}$ NPHIs also vary in their regulatory roles and in their position and independence within government. While many NPHIs report 


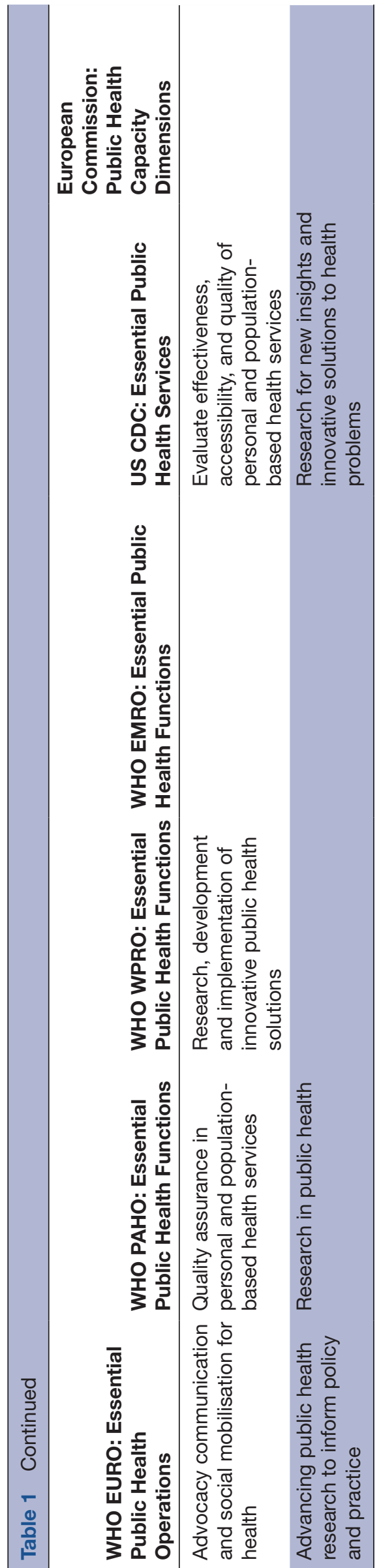

directly to their country's ministry of health, others exist as autonomous government agencies with a variety of alternative arrangements existing, yet a certain degree of independence is necessary for NPHIs to be effective organisations. ${ }^{1}$ Their technical and operational mandate allows NPHIs to provide quality, evidence-based advice, reducing the risk of being driven by political ideology or financial incentive. ${ }^{3}$

NPHIs are playing an increasing role in building capacity for global health security (GHS), for example, the recent establishment of the Nigeria Centre for Disease Control, and its effective response to outbreaks of Ebola, Lassa fever and Monkeypox in the region demonstrates what an NPHI can achieve with good leadership. ${ }^{4}$ While precise definitions of GHS vary, there is little doubt that the most important legal instrument for framing the issue globally is the International Health Regulations (IHR 2005). Using the IHR, WHO supports member states worldwide in developing National Action Plans for Health Security to address the identified gaps in these capacities. ${ }^{5}$ However, acting to address these gaps requires effective co-ordination of a wide range of public health capabilities, ${ }^{6}$ and commentators have highlighted that sufficient focus on national-level health security strengthening is lacking, as is the ownership of the agenda by LMICs. ${ }^{7}$ In its inaugural 2019 report, the Global Preparedness Monitoring Board highlighted that countries still have much to do prepare for a rapidly spreading pandemic with both stronger national systems and better global, regional and country networks needed. ${ }^{8}$ NPHIs, through their consolidation of essential public health functions and potential for cross-sectoral linkages, are well placed to systematically address weaknesses in IHR compliance if sufficiently empowered legally and resourced.

National capacity alone, however, is insufficient to ensure adequate strengthening of preparedness for epidemics. In our globalised world, outbreaks are not contained by national borders and therefore achieving good GHS requires more than this. In West Africa, Meda et al have argued that regionally networked public health institutes should be operationalised to provide regional strengthening and thus reduce the risk of recurrence of an outbreak such as Ebola. ${ }^{9}$ As such, while NPHIs operate at a national level, in recent years, there has been a growing trend of international networking and partnerships between them, with structured peer-to-peer support resulting in improvements in many collaborating organisations. ${ }^{10}$ These collaborations have strengthened diverse aspects of NPHIs, from specific areas such as outbreak response capacity to improved governance and workforce development. ${ }^{11}$ In an increasingly complex and sometimes fragmented global health architecture, IANPHI with over a hundred members across 95 countries serves an important function in fostering these relationships and facilitating collaborations between these national agencies. While partnerships have traditionally developed through historical, cultural and political bilateral links, more recently, new co-ordination 
mechanisms have been developed to allow countries to collaborate and support each other more systematically in addressing public health challenges. ${ }^{12}$ Current collaborative programmes relate to a range of global public health priorities including universal health coverage, GHS and non-communicable disease (NCD) control and are enabled by the strong commitment, capabilities and experience across its global network. With an increasing burden of NCDs falling on LMICs globally, the development of the capacities of NPHIs to monitor and prevent these diseases will become increasingly important. This has led to IANPHI grants being used to develop NPHI capacity in the surveillance and prevention of NCDs across the network, including in Costa Rica, Colombia, Nigeria and Tanzania. ${ }^{11}$

Such activities complement WHO's functions as a normative, standard setting UN agency, by helping operationalise and implement its guidance at a national level. While WHO excels at standard setting, convening stakeholders, communicating global risks and political engagement, it has increasingly been drawn in to being an operational agency leading outbreak responsethus further straining its already stretched budget and capacity. ${ }^{13}$ NPHI networks like IANPHI can help alleviate some of this strain by facilitating operational capability being developed, transferred and owned at the national level-a process that can be further strengthened through peer support and the establishment of longterm and supportive institutional partnerships across a network of NPHIs. In the context of preparedness, this national ownership and long-term focus on operational capabilities is vital and is an approach that Africa Centre for Disease Control and Prevention (Africa CDC) has set out to support, engaging with IANPHI's network of African NPHIs. ${ }^{14}$ In addition, such networks can address more than just GHS, with potential to strengthen the full breadth of essential public health functions.

The European CDC model of a network of NPHIs across the European Region, which shares data and learning and collaborates in support of Field Epidemiological Training, helping to build professional connections through shared training, would serve Africa well and is the approach being championed by John Nkengasong, the Director of Africa CDC. ${ }^{15}$ This approach will allow Africa CDC to remain a relatively lean and efficient organisation which draws strength from the network and avoids the cost of a large and potentially expensive model of concentrating significant technical capacity at regional and subregional hubs. Supporting the development of strong NPHIs helps avoid the cost of displacing public health professionals from their own countries, which can ill afford their absence, while still enabling those national experts to gain international experience through Africa CDC co-ordinated operations. The value of international exchanges and deployments for building internationally deployable capability that meets national, regional and also GHS needs is well illustrated by the current demand for expertise from across Africa, and globally, to support the Ebola response in the Democratic Republic of Congo. European CDC is exploring collaboration with Africa CDC and will be an important partner in Africa CDC's growing global network of connections.

\section{LIMITATIONS AND OPPORTUNITIES}

With a small central funding pot derived primarily through membership subscriptions, IANPHI only has a limited ability to deliver capacity-building programmes to scale in all member regions. However, with its large global network already established, IANPHI represents a significant untapped resource to support normative, standard-setting agencies such as WHO deliver on their mandate through direct capacity building and operational support to Member States. Increased central funding for IANPHI through an increase in member contributions, especially from NPHIs in wealthier states, coupled with external funding from donors would be necessary to enable the network to truly leverage its broad array of institutional links and develop long-term peer-supported programmes.

Relatively resource-rich NPHIs, such as the Robert Koch Institute (RKI) in Germany, the US CDC and Public Health England (PHE), have extensive expertise not just in public health delivery but also international capacity building. Institutions such as these with long histories have undergone significant organisational change, including of governance arrangements and public health remit and have valuable experience that can potentially benefit others looking to establish strong, effective NPHIs-both in terms of best practice to adopt and in terms of mistakes made to avoid. The RKI, for example, was first established in 1891 as the Royal Prussian Institute of Infectious Diseases, with a limited focus in scope and geography, and survived through the conflict and change of the 20th century to emerge as a world-leading public health agency. ${ }^{16}$

Many NPHIs in LMICs have limited resource and influence and have to function in fragmented and under-resourced health systems. In particular, it can be difficult to fulfil surveillance and monitoring functions when laboratory systems are not integrated, either functioning as part of vertical disease-specific programmes or in the privatesector, or with their quality assurance and management under the control of other bodies. ${ }^{17}$ There is a need for effective linkages between NPHIs and other parts of the public health system in order to fulfil essential public health functions. Similarly, many NPHIs in LMICs often face significant limitations in relation to staffing and workforce development. There has been real success in addressing some of these issues with the development of field epidemiology training programmes and networks of schools of Public Health. These initiatives have helped to build capacity to improve surveillance and respond to outbreaks in particular, ${ }^{18}$ and have helped to ensure that the academic institutions that develop the public health workforce are responsive to service needs. ${ }^{19}$ 
In the European Region, WHO EURO Regional Office has been working with IANPHI and the Association of Schools of Public Health in the European Region (ASPHER) to develop competency-based public health training. Competency-based training has been the backbone of the development of the UK's public health system, recognising that public health leadership requires more than a Masters degree in Public Health, but a wider range of other competencies which build leadership and diplomacy skills, as well as in health protection, promotion, improvement and healthcare public health. ${ }^{20}$ A meeting convened by the Association of Schools of Public Health in the Africa Region has initiated the process of adapting the European competency framework to meet Africa's public health challenges. ${ }^{21}$

Strong public health networks also have the potential to strengthen their members effectiveness by enabling the pooling of regional resources. Developing new or small NPHIs may add further bureaucracy and inefficiencies into public health systems, and therefore, as such initiatives are undertaken, it is essential that appropriate cost analyses are performed and resources shared where feasible to do so. Ensuring NPHIs have the required level of core resource capacity is likewise essential as a minimum level of staffing, experience and finance is required for the organisation's success. Lessons learnt from the network should help to address this.

Limitations can also extend to questions around just how independent NPHIs really are. PHE, for example, an executive agency of the UK Department for Health and Social Care with operational autonomy, exercises its independence by speaking to the evidence. However, this has not prevented occasional criticism by those who would like to see greater challenge of the government on public health issues. ${ }^{22}$ The US CDC is limited by statute in how it can tackle firearm-related deaths and injuries, or even undertake research on the topic. ${ }^{23}$

\section{POTENTIAL FOR ENHANCED GLOBAL PUBLIC HEALTH}

The network, therefore, has the potential to facilitate both north-south and south-south partnerships, with this latter model of support offering perhaps the most powerful potential to enable sustainable development; mobilising the experience of IANPHI members most in tune to the practicalities of how to best support southern partners especially when making difficult choices in resource-constrained settings. This approach to capacity building aligns well with the Global Preparedness Monitoring Board's call to develop global and regional networks to help with preparedness and disease control. ${ }^{8}$ Case studies of successful initiatives may act as evidencebased advocacy tools for members looking to develop in a similar direction.

The potential of IANPHI to strengthen international collaboration and capacity building has been demonstrated through the Bill and Melinda Gates funding of IANPHI's Child Health and Mortality Surveillance programme, which collects and shares country data on child mortality in order to provide timely information that can inform health system response, a programme that has only been possible as a result of collaboration between NPHIs. ${ }^{24}$ Increased donor funding to expand this approach to cover a wider range of public health collaboration, in partnership with WHO, would help catalyse the capacity building already being championed by Africa CDC and build a more vibrant and active global network of peer-to-peer support to build national public health capability.

Peer learning has been gaining increased attention in recent years. As a model of development, it presents a flexible alternative to traditional methods, with a shared approach that enables the transfer of knowledge from all participants with mutual learning. ${ }^{25}$ For NPHIs, this translates to the establishment of long-term relationships between organisations which can support each other in the pursuit of the delivery of public health to an ambitious, internationally agreed on, evidence-based standard. This is undertaken using needs analysis, mapping and partnering, thus empowering members to receive tailored support while also offering all the opportunity to participate in regional and international systems strengthening. This approach supports nationally identified priorities rather than those set by external donors and stakeholders. By locating such projects within NPHIs, sustainability is likewise facilitated.

To achieve WHO's 'triple billion' goal, to see 1 billion more people benefit from universal health coverage, 1 billion more people better protected from health emergencies and 1 billion more people enjoying improved health and well-being, the organisation will need to extend its partnership work, a direction it signals towards in its 13th General Programme of Work. ${ }^{26}$ As part of this strategic shift, there is a drive for technical partnerships to build national institutions and the IANPHI network is a natural partner for $\mathrm{WHO}$, having the potential to play a vital role in delivering on its priorities.

On 28 February 2019 at a meeting hosted by WHO in Geneva, IANPHI and ASPHER agreed that collaboration with WHO to support public health capacity development would be of value beyond GHS priorities, as the public health skills and competencies needed to protect population health of the group of professionals who lead this response are the same as those who must also support health systems developed to address the rising burden of NCDs, where disease prevention, health promotion and understanding disease epidemiology will be as important as healthcare to manage the rapidly escalating costs of services for chronic diseases and ageing populations.

\section{CONCLUSION}

Scaling up these broadly implemented peer-to-peer collaborations across an international network of NPHIs represents a valuable new mechanism for enhancing global public health. With an appetite for national 
strengthening to complement internationally focused public health initiatives, such an approach offers a promising direction to support the public health system globally. In order to achieve this, NPHIs across the network will need to commit resources, in particular in terms of technical expertise, and funding sources must be identified either from network members or external donors. To achieve its full potential, the network would benefit from closer partnership with WHO, with the resulting relationship helping to achieve WHO's triple billion targets. Both IANPHI and WHO should continue to work together to facilitate the operationalisation of this network through identifying funding streams and streamlining NPHI strengthening programmes with WHO's existing programmes. Questions remain around the limitations facing some NPHIs as well as the minimum standards required to deliver effective essential public health functions, but the network itself has the potential to explore solutions for such concerns. The ability to empower institutes from LMICs and facilitate the upscaling of regional capacity likewise contributes to the conclusion that these networks represent a promising way forward for the further operationalisation of public health capacity.

Contributors RV prepared the initial draft of the paper. RV, OM-A, OD and NS contributed to review and editing. All authors have experience in global public health and have been engaged with WHO and the International Association of National Public Health Institutes in the discussion around the operationalisation of networks of National Public Health Institutes. NS is the Director of Global Public Health at Public Health England.

Funding The authors have not declared a specific grant for this research from any funding agency in the public, commercial or not-for-profit sectors.

Competing interests RV, OM-A, OD and NS have worked for Public Health England.

Patient consent for publication Not required.

Provenance and peer review Not commissioned; externally peer reviewed.

Data availability statement There are no data in this work

Open access This is an open access article distributed in accordance with the Creative Commons Attribution Non Commercial (CC BY-NC 4.0) license, which permits others to distribute, remix, adapt, build upon this work non-commercially, and license their derivative works on different terms, provided the original work is properly cited, appropriate credit is given, any changes made indicated, and the use is non-commercial. See: http://creativecommons.org/licenses/by-nc/4.0/.

ORCID iD

Robert Verrecchia http://orcid.org/0000-0002-9773-8735

\section{REFERENCES}

1 Frieden TR, Koplan JP. Stronger national public health Institutes for global health. Lancet 2010;376:1721-2.

2 World Health Organization. Essential public health functions, health systems and health security: developing conceptual clarity and a WHO roadmap for action, 2018. Available: https://apps.who.int/iris/ handle/10665/272597 [Accessed 26 Jun 2019].

3 Binder S, Adigun L, Dusenbury C, et al. National public health Institutes: contributing to the public good. $J$ Public Health Policy 2008;29:3-21.
4 Njidda AM, Oyebanji O, Obasanya J, et al. The Nigeria Centre for Disease Control. BMJ Global Health 2018;3:e000712.

5 World Health Organisation. WHO benchmarks for international health regulations (IHR) capacities, 2019. Available: https://www.who.int/ ihr/publications/9789241515429/en/ [Accessed 26 Jun 2019].

6 Mghamba JM, Talisuna AO, Suryantoro L, et al. Developing a multisectoral national action plan for health security (NAPHS) to implement the International Health Regulations (IHR 2005) in Tanzania. BMJ Glob Health 2018;3:e000600.

7. Ravi SJ, Snyder MR, Rivers C. Review of international efforts to strengthen the global outbreak response system since the 2014-16 West Africa Ebola epidemic. Health Policy Plan 2019;34:47-54

8 Global Preparedness Monitoring Board. A world at risk: annual report on global preparedness for health emergencies. Available: http://apps.who.int/gpmb/annual_report.html [Accessed $20 \mathrm{Sep}$ 2019].

9 Meda N, Dabis F, Desenclos J-C, et al. Network for strong, national, public health institutes in West Africa. The Lancet 2016;387:2196-7.

10 Pekka P, Jeffrey KP, Koplan J. IANPHI-10 years of collaboration for institutional public health. Eur J Public Health 2017;27:192-3.

11 International Association of National Public Health Institutes. IANPHI 10 year report, 2016. Available: https://indd.adobe.com/view/ 2fc92296-5160-40ec-b8dc-ad8332efe162 [Accessed 26 Jun 2019].

12 Bergh A, Desenclos JC, Forland F, et al. National public health Institutes collaborate with WHO to promote global health security. World Health Organisation Weekly Epidemiological Record 2019;94:xxi-xxiv.

13 Reddy SK, Mazhar S, Lencucha R. The financial sustainability of the World Health Organization and the political economy of global health governance: a review of funding proposals. Global Health 2018;14:119.

14 Nkengasong JN, Maiyegun O, Moeti M. Establishing the Africa Centres for Disease Control and Prevention: responding to Africa's health threats. Lancet Glob Health 2017;5:e246-7.

15. The Lancet Infectious Diseases. A new day for African public health Lancet Infect Dis 2017;17:237.

16 Robert Koch Institute. The Robert Koch Institute: one of the world's oldest biomedical institutes, 2018. Available: https://www.rki.de/ EN/Content/Institute/History/history_node_en.html;jsessionid=86A5 5D752E4EF8D563FE2792721FB0CD.1_cid363 [Accessed 26 Jun 2019]

17. Onyebujoh PC, Thirumala AK, Ndihokubwayo J-B. Integrating laboratory networks, surveillance systems and public health Institutes in Africa. Afr J Lab Med 2016;5.

18 Jones DS, Dicker RC, Fontaine RE, et al. Building global epidemiology and response capacity with field epidemiology training programs. Emerg Infect Dis 2017;23.

19 Otok R, Czabanowska K, Foldspang A. Public health educational comprehensiveness: the strategic rationale in establishing networks among schools of public health. Scand J Public Health 2017;45:720-2

20. Foldspang A, Birt C, Otok R. ASPHER's European List of Core Competences for the Public Health Professional 5th Edition. Scand $J$ Public Health 2018;46:1-52.

21 Association of Schools of Public Health in Africa. Communique from 2018 ASPHA conference, 2018. Available: https://asphaafrica.net/ communique-2018-aspha-conference/ [Accessed 19 Jun 2019].

22 Buck D. Public Health England: speaking up and speaking truth to power? 2014. Available: https://www.kingsfund.org.uk/blog/2014/ 03/public-health-england-speaking-and-speaking-truth-power [Accessed 26 June 2019].

23. The Lancet. Gun deaths and the gun control debate in the USA Lancet 2017:390.

24 Gulland A. Gates funds surveillance site to prevent next big epidemic. BMJ 2015;350:h2534.

25 Effective Institutions Platform and National School of Government International. The future of peer-to-peer learning and partnerships in the new development agenda, 2018. Available: https://www. effectiveinstitutions.org/media/The_Future_of_Peer_to_Peer_ Partnerships_in_the_New_Development_Agenda.PDF [Accessed 26 Jun 2019].

26 World Health Organisation. Draft thirteenth general programme of work 2019-2023. World Health Assembly, 2018: A71/4. 